\section{Cassia Maria Buchalla}

Departamento de Epidemiologia da Faculdade de Saúde Pública da Universidade de São Paulo (USP)

\title{
Resenha acadêmica descritiva
}

O livro Artigos Científicos: como redigir, publicar e avaliar, de autoria do Prof. Mauricio Gomes Pereira, foi lançado recentemente pela Editora Guanabara Koogan.

Com o objetivo de orientar os potenciais autores sobre como vencer as muitas barreiras na elaboração e publicação de artigos científicos, o livro aborda cada uma das etapas desse processo em 24 capítulos.

Os três primeiros capítulos tratam dos aspectos da preparação do trabalho. O primeiro capítulo, Pesquisa e Comunicação Cientifica, versa sobre a necessidade de divulgação dos resultados das pesquisas como forma de finalização da mesma. Aborda, de modo geral, a evolução da comunicação cientifica nas ciências da saúde, menciona os periódicos de acesso livre e a situação atual de elevada competição para publicar .

No segundo capítulo, Canais de Comunicação Cientifica, o autor descreve os tipos de periódicos, os tipos de artigos, as formas de publicação e as normas que as regem.

Do terceiro ao décimo quinto capítulo é apresentada cada parte da estrutura de um trabalho cientifico, começando pelo planejamento, abordando a estrutura, redação e revisão do texto, a introdução, o método, os resultados, a discussão, as referências bibliográficas, o título, a autoria, o resumo, as palavras-chave, a escolha do periódico e um capítulo com temas para a complementação do artigo (capítulo 15).

Somam-se a esse conjunto de capítulos, que orientam a elaboração de cada seção do artigo cientifico, outros três capítulos que exploram a Estatística (capítulo 18), a Preparação de Tabelas (capítulo 19) e a Preparação de Figuras (capítulo 20).

O leitor irá encontrar também capítulos sobre a Submissão do Artigo para a Publicação, sobre a Avaliação de artigo Cientifico e sobre Ética (capítulo 21).

Os três últimos capítulos do livro versam sobre temas auxiliares, enfocando a motivação para divulgar os resultados de uma pesquisa e os recursos para publicá-los. O capítulo 22, Vale a pena publicar Artigo Científico?, lista os motivos pelos quais esta prática é cada vez mais importante e competitiva assim como os auxílios disponíveis para uma escrita de qualidade. O capitulo seguinte, Como ter Artigo aprovado para Publicação, aponta as particularidades dos textos recusados, como falta de relevância do tema, pouca originalidade, os erros mais comuns de redação, entre outros aspectos que devem ser evitados para que um trabalho seja aprovado para publicação.

O livro termina com Síntese das Sugestões sobre Redação Científica, onde são agregadas as informações que resumem os demais capítulos do livro.

Os capítulos são estruturados em itens, apresentados com texto curto e com um ou mais exemplos, quando pertinente. A estrutura do texto obedece a lógica de apresentação de cada tópico, do geral ao especifico, havendo dois itens comuns a todos os capítulos, o item Sugestões e outro com Comentário final.

Os temas são apresentados com uma linguagem clara e direta. Além disso, vários recursos utilizados pelo autor facilitam a leitura, como a inclusão de exemplos e o resumo do conteúdo de cada capítulo, apresentado em tabela, fazendo referência à seção onde cada tema aparece.

O leitor pode esperar instruções sobre cada etapa do processo de elaboração de um texto científico para publicação, com a exposição de cada detalhe envolvido e dicas sobre o que deve ser considerado para se obter um resultado apropriado.

Além disso, aspectos importantes relacionados ao encaminhamento e à publicação do artigo são abordados na obra. Entre esses, como preparar uma carta ao editor, como lidar com o processo de revisão, e como proceder para avaliar um artigo cientifico.

A inclusão de um capítulo sobre esta- 
tística, assim como sobre a preparação de tabelas e figuras reflete a abrangência da obra. Nota-se, em toda a obra, uma abordagem além do que seria esperado para os temas propostos.

O autor não se limita a identificar o conteúdo básico de cada item de um artigo cientifico e a explorar formas de preparar cada parte do trabalho, oferecendo ao leitor a chance de rever cada tópico da preparação do estudo. Por exemplo, o capítulo de Método aborda detalhes de cada um dos seus itens como tipos de estudo, características da amostra, classificação das variáveis, erros a serem evitados, entre outros. No capítulo Resultados, somado à seqüência de apresentação dos dados, o autor também descreve as formas estatísticas para apresentar o efeito encontrado no estudo.

No capítulo sobre Complementação do Artigo o leitor encontrará instruções sobre as revisões para o aprimoramento do artigo, os erros e os vícios de linguagem a serem evitados, normas para o uso de siglas e de citação de números no texto, tempos verbais a serem usados em cada parte do artigo, entre outros aspectos necessários a uma redação correta.

A abrangência do conteúdo torna inevi- tável algumas repetições, até porque alguns temas apresentados se sobrepõem.

Ainda que o foco seja a redação de artigo cientifico, é evidente a quantidade de informação teórica sobre pesquisa epidemiológica disponibilizada. O livro não se limita a propor normas de redação, como uma receita do que deve conter a introdução, a parte de métodos ou as demais partes do artigo, mas inclui um conteúdo teórico sobre temas relacionados a cada tópico. Desta forma, o livro pode ser útil para aqueles que querem um roteiro ou orientação para aprimorar seus manuscritos científicos e que têm dúvidas específicas, mas também para os iniciantes, que se beneficiarão ao ler um texto mais extenso, com um teor maior de informação sobre cada aspecto envolvido na produção cientifica.

O autor, Dr. Mauricio Gomes Pereira, é médico com especialização em pediatria e em saúde pública e professor titular da Universidade de Brasília. Tem vários livros publicados, entre eles Epidemiologia:teoria e prática, e vasta experiência na área de metodologia científica e de epidemiologia. O livro Artigos Científicos: como redigir, publicar e avaliar torna maior sua contribuição para o ensino e a pesquisa no Brasil. 